\title{
Intrinsic patient factors predictive of inpatient rehabilitation facility discharge following primary total knee arthroplasty: a systematic review and meta-analysis
}

\author{
Larissa Sattler $^{1^{*}}$ (D), Wayne Hing ${ }^{1}$, Evelyne Rathbone ${ }^{1}$ and Christopher Vertullo ${ }^{2}$
}

\begin{abstract}
Background: Total Knee Arthroplasty (TKA) reduces pain and improves function in those suffering from severe osteoarthritis. A significant cost of TKA is post-acute care, however, current evidence suggests that discharge to an Inpatient Rehabilitation Facility (IRF) has inferior outcomes to home discharge, with no greater benefit in physical function. Only individual studies have investigated TKA patient characteristics predictive of discharge destination, therefore, the aim is to systematically review the literature and meta-analyse intrinsic patient factors predictive of IRF discharge. If predictive factors are known, then early discharge planning and intervention strategies could be implemented.

Methods: Databases PubMed, CINAHL, Embase, Cochrane, and Pedro were searched up to October 2019 for all studies investigating pre-operative intrinsic patient factors predictive of IRF discharge. For assessing the methodological quality of included studies, the Quality In Prognosis Studies (QUIPS) tool was used. Statistical analysis and graphical reporting were conducted in $\mathrm{R}$ statistical software. To assess the effect of predictors of discharge destination, odds ratios with the corresponding $95 \% \mathrm{Cl}$ were extracted from the results of univariate and multivariable analyses.

Results: A total of 9 articles published between 2011 to 2018 with 218,151 TKA patients were included. Of the 13 intrinsic patient factors reported, 6 met the criteria for synthesised review: age, obesity, comorbidity, gender, SF-12NR-12 survey, and smoking. Due to the heterogeneity of statistical analysis and reporting 2 variables could undergo meta-analysis, gender and smoking. Female gender increased the likelihood of IRF discharge by $78 \%(\mathrm{OR}=1.78 ; 95 \% \mathrm{Cl}=1.43-2.20 ; 12=$ $33.3 \%)$, however, the relationship between smoking status and discharge destination was less certain $(\mathrm{OR}=0.80 ; 95 \% \mathrm{Cl}=$ $0.42-1.50 ; 12=68.5 \%)$.

* Correspondence: Isattler@bond.edu.au

${ }^{1}$ Bond University, Bond Institute of Health and Sport, Promethean Way, Robina, QLD 4226, Australia

Full list of author information is available at the end of the article

(c) The Author(s). 2020 Open Access This article is licensed under a Creative Commons Attribution 4.0 International License, which permits use, sharing, adaptation, distribution and reproduction in any medium or format, as long as you give appropriate credit to the original author(s) and the source, provide a link to the Creative Commons licence, and indicate if changes were made. The images or other third party material in this article are included in the article's Creative Commons licence, unless indicated otherwise in a credit line to the material. If material is not included in the article's Creative Commons licence and your intended use is not permitted by statutory regulation or exceeds the permitted use, you will need to obtain permission directly from the copyright holder. To view a copy of this licence, visit http://creativecommons.org/licenses/by/4.0/ The Creative Commons Public Domain Dedication waiver (http://creativecommons.org/publicdomain/zero/1.0/) applies to the data made available in this article, unless otherwise stated in a credit line to the data. 


\begin{abstract}
(Continued from previous page)
Conclusion: In this systematic literature review and meta-analysis female gender was shown to be predictive of IRF discharge after total knee arthroplasty. There was also a trend for those of older age and increased comorbidity, as measured by the Charlson Comorbidity Index, or the severely obese to have an increased likelihood of IRF discharge. The marked heterogeneity of statistical methods and reporting in existing literature made pooled analysis challenging for intrinsic patient factors predictive of IRF discharge after TKA. Further, high quality studies of prospective design on predictive factors are warranted, to enable early discharge planning and optimise resource allocation on post-acute care following TKA.
\end{abstract}

Trial registration: This review was registered with PROSPERO (CRD42019134422).

Keywords: Total knee arthroplasty (TKA), Rehabilitation, Discharge, Predictors, Systematic review, Meta-analysis

\section{Background}

From 2014 to 2030 in the United States, primary total knee arthroplasty (TKA) is projected to increase by $85 \%$ to 1.26 million surgical procedures [1]. TKA is widely regarded as a cost-effective intervention for end-stage knee osteoarthritis, improving both a patient's functional status and overall health quality [2]. However, with the societal burden of cost for TKA increasing, there is a need to evaluate the economic efficiency of current models of care $[3,4]$.

Total Joint Arthroplasty (TJA) is reportedly the most frequent procedure leading to post-acute admission to an Inpatient Rehabilitation Facility (IRF), representing one of the most significant costs associated with TKA $[4,5]$. Acute post-discharge care following primary TKA can account for up to $37 \%$ of the total procedure cost, with home discharge reported as costing $\$ 16,000$ less than discharge to an IRF in the United States [6, 7]. While IRF patients receive multidisciplinary input such as physical therapy and occupational therapy, this has yet to translate into evidence for improved functional outcomes when compared with TKA patients discharged directly to home $[8,9]$. Moreover, retrospective studies relying on administrative datasets have shown TKA patients with an IRF discharge have a significantly higher adverse event and 30-day readmission rate compared to those discharged home [10, 11].

The decision to discharge a patient to an IRF is dependent on many variables and identifying preoperative factors that increase the likelihood of IRF discharge will better facilitate pre-operative discharge planning and resource allocation. Given an estimated 1.82 billion is spent on IRF discharge after lower-extremity arthroplasty it is imperative to determine which factors create a higher risk for non-home discharge [12]. To date, only individual studies have investigated TKA patient characteristics predictive of discharge destination, therefore, the aim of this review was to systematically review the literature and conduct a meta-analysis on reported intrinsic patient factors predictive of IRF discharge.

\section{Methods}

This systematic review and meta-analysis was prospectively registered on PROSPERO (International prospective register of systematic reviews), registration CRD42019134422 and is reported in accordance with the guidelines from the PRISMA (Preferred Reporting Items for Systematic Reviews and Meta-Analyses) statement [13].

\section{Search strategy}

Relevant online databases PubMed, Cumulative Index to Nursing and Allied Health (CINAHL), Embase, Cochrane, and Pedro were systematically searched from database inception to October 3rd, 2019. Key terms were identified for the search, including knee arthroplasty, predictor, and discharge, as well as synonym words, utilising Medical Subject Heading and Boolean operator terms. The complete search strategy is reported in Table 1.

\section{Study eligibility}

We included all articles of any study design investigating pre-operative patient factors for their level of predictivity of IRF discharge following primary TKA. Key inclusion criteria were that the article be available in full text English, a search term was required in the title or abstract, the population studied was primary unilateral knee replacement patients, a pre-operative intrinsic patient factor was a variable in the study and an outcome included discharge destination. Intrinsic factors were defined as those inherent to the individual, including demographic characteristics age, gender, ethnicity, socioeconomic status as well as clinical factors such as presence of comorbidity. Behavioural factors such as smoking and alcohol consumption, and patient reported outcome measures that capture the patient's perspective were also considered intrinsic factors and included. Non-intrinsic factors were excluded, where the patient was subject to an intervention such as participation in a pre-operative exercise class or education session. Additional exclusion criteria were post-operative variables including length of 
Table 1 Critical review databases and search terms

\begin{tabular}{|c|c|c|c|c|c|}
\hline Database & Search Terms & & & & \\
\hline $\begin{array}{l}\text { PubMed } \\
\text { CINAHL } \\
\text { Embase } \\
\text { COCHRANE } \\
\text { PEDro }\end{array}$ & $\begin{array}{l}\text { "Arthroplasty, Replacement, } \\
\text { Knee" (MESH) } \\
\text { OR } \\
\text { Knee Replacement } \\
\text { OR } \\
\text { TKR }\end{array}$ & AND & $\begin{array}{l}\text { Predict* } \\
\text { OR } \\
\text { Determin* } \\
\text { OR } \\
\text { Preoperative OR } \\
\text { Factors } \\
\text { OR } \\
\text { Characteristic* } \\
\text { OR } \\
\text { Influence } \\
\text { OR } \\
\text { Affects }\end{array}$ & AND & $\begin{array}{l}\text { Discharge* } \\
\text { OR } \\
\text { "Patient Discharge"[Mesh]) }\end{array}$ \\
\hline
\end{tabular}

${ }^{*}=$ truncation search

stay (LOS), readmission status and other post-operative complications. Studies that did not separate the reporting of primary TKA were also excluded, as were studies that took place after discharge from the post-acute hospital setting, such as outpatient or inpatient rehabilitation.

\section{Study selection}

Based on the inclusion criteria, an initial screening of titles and abstracts was conducted, next, a screening of extracted full text papers was conducted for final review. Those studies that met the inclusion/exclusion criteria for this literature review were then screened for eligibility to be included for meta-analysis.

\section{Data extraction}

A modified form based on the Critical Appraisal and Data Extraction for Systematic Reviews of Prediction Modelling Studies (CHARMS) Checklist was used for data extraction [14]. Data regarding author, year of publication, country, study design, exclusion criteria, patient factors investigated, sample size, participant age and gender as well as a description of statistical analysis undertaken were included.

\section{Quality assessment}

For assessing the quality of individual studies, the Quality In Prognosis Studies (QUIPS) tool was applied [15]. The QUIPS tool is a validated tool for assessing risk of bias in prognostic factor studies and provides a qualitative assessment of six domains: (I) Study Participants, (II) Study Attrition, (III) Prognostic Factor Measurement, (IV) Outcome Measurement, (V) Study Confounding and (VI) Statistical Analysis and Reporting [16]. For each of these 6 domains, the responses 'yes', 'partial', 'no' or 'unsure' for three up to seven items within each domain are combined to assess the risk of bias. Two reviewers, following the guidelines of Hayden et al. 2013 [16] independently assessed each study, ranking the risk of bias as high, moderate or low. If the authors disagreed on the risk of bias rating, a consensus agreement was reached by joint discussion.

\section{Statistical analysis}

Statistical analysis and graphical reporting were conducted in $\mathrm{R}$ statistical software, version 3.5.3 [R-Core], using packages metafor and forestplot [17]. To assess the effect of predictors of discharge destination, odds ratios with the corresponding 95\%CI were extracted from the results of univariate and multivariable analyses. When these effect sizes were not reported in univariate results, they were computed from the count data, if available.

Meta-analysis of a patient factor was considered where there was a minimum of three studies reporting an association between the predictor and discharge destination. Meta-analysis was only applied to a factor if the reference categories were similar. Forest plots without pooled effect were produced for those studies considered ineligible for meta-analysis to gain insight into the degree of predictability of the patient factor. Heterogeneity of included studies' estimates were assessed by computing the $I^{2}$ statistic and was considered statistically significant at $P<0.10$. $I^{2}$ values were used to describe the percentage of total variation across studies; an $I^{2}$ value of $25 \%$ was considered low, 50\% moderate, and 75\% high [18]. Pooling of the odds ratios across studies was carried out with a randomeffects model using the inverse-variance method.

\section{Results}

\section{Literature search and study characteristics}

The results of the search strategy and screening process are shown as a flowchart in Fig. 1. After duplicates were removed, 1557 articles were screened for eligibility with reasons for exclusion listed. A total of 9 articles published between 2011 to 2018, with 218,151 TKA patients, were included in this review [19-27]. Of those, 4 articles [22-24, 27] met the criteria to undergo meta-analysis.

The individual studies and their characteristics can be found in Table 2. Patient demographics were similar across studies for mean age ranging from 61 to 70 years, 


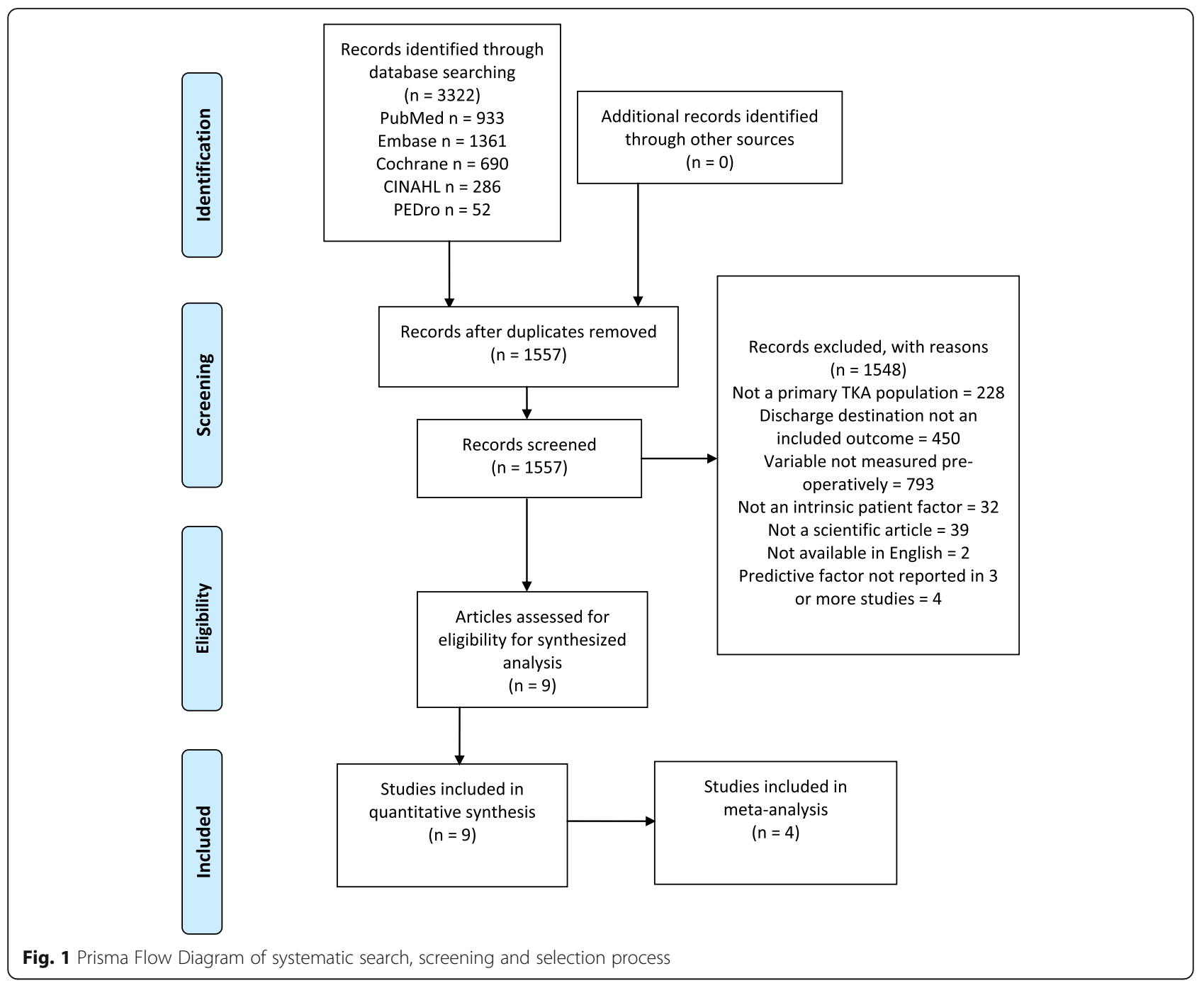

however, female gender had greater variation, ranging from 56 to $83 \%$ of the study populations. Country of origin was the United States for 8 of the 9 papers, with 1 being from Australia. All studies were of observational cohort design, 7 were performed retrospectively.

\section{Methodical quality}

QUIPS ranking did not vary by more than one category between raters for any criteria for each publication and consensus was achieved by discussion. Table 3 presents the risk of bias scores for all included studies. The risk of bias was ranked low across all studies for "study participation," "prognostic factor measurement," and "outcome measurement." However, "study confounding," was ranked moderate or high for risk of bias across 6 of the 9 studies. As 8 of the 9 studies did not report on perioperative factors such as surgical and anaesthetic technique or physical therapy protocols this could have a confounding effect on the other patient factors assessed.

\section{Intrinsic patient factors analysed}

Patient factors in the included studies that were analysed for their association with discharge destination were age, American society of anaesthesiology (ASA) score, body mass index (BMI), Charlson comorbidity index (CCI), diabetes, gender, ethnicity, haemoglobin $(\mathrm{Hb})$, knee range of motion (ROM), socioeconomic status (SES), 12 item short form health survey or 12 item Veteran's RAND health survey (SF-12/VR-12), smoking and venous thromboembolism (VTE) history. Table 4 details the predictability of each patient factor on discharge destination for the included studies. Of the 13 patient factors reported on, 6 factors met the criteria for comparison and a synthesised review, these were age, BMI, CCI, gender, SF-12/VR-12 survey, and smoking status.

\section{Demographic factors}

The patient factor gender was able to undergo metaanalysis in 4 studies [22-24, 27] to provide results of a combined effect on predictability of discharge 
Table 2 Study Characteristics

\begin{tabular}{|c|c|c|c|c|c|c|c|}
\hline $\begin{array}{l}\text { Author, Year. } \\
\text { Country }\end{array}$ & Study Title & $\begin{array}{l}\text { Study design; } \\
\text { Exclusion criteria (if provided) }\end{array}$ & $\begin{array}{l}\text { Patient } \\
\text { Factors }^{\mathbf{a}}\end{array}$ & $\begin{array}{l}\text { TKA } \\
\text { Patients } \\
(\mathbf{N})\end{array}$ & $\begin{array}{l}\text { Age: } \\
\text { mean } \\
( \pm S D \\
\text { or } \\
\text { range })\end{array}$ & $\begin{array}{l}\text { Female } \\
\text { Gender: } \\
\boldsymbol{n}(\%)\end{array}$ & $\begin{array}{l}\text { Statistical } \\
\text { Analysis }^{\mathbf{a}}\end{array}$ \\
\hline $\begin{array}{l}\text { Anoushiravani } \\
\text { et al., } 2016 . \\
\text { USA }\end{array}$ & $\begin{array}{l}\text { Assessing In-Hospital Outcomes and } \\
\text { Resource Utilization After Primary } \\
\text { Total Joint Arthroplasty Among } \\
\text { Underweight Patients. }\end{array}$ & $\begin{array}{l}\text { Retrospective matched cohort:; } \\
\text { Weight loss and obesity, due to the } \\
\text { nature of the study, were excluded } \\
\text { from the matching criteria. }\end{array}$ & BMI & 1315 & $\begin{array}{l}70 \\
(15- \\
91\end{array}$ & $\begin{array}{l}1029 \\
(78)\end{array}$ & Univariate \\
\hline $\begin{array}{l}\text { Crawford } \\
\text { et al., } 2011 . \\
\text { USA }\end{array}$ & $\begin{array}{l}\text { Preoperative Predictors of Length of } \\
\text { Hospital Stay and Discharge } \\
\text { Disposition Following Primary Total } \\
\text { Knee Arthroplasty at a Military } \\
\text { Medical Center. }\end{array}$ & $\begin{array}{l}\text { Retrospective cohort; } \\
\text { Bilateral, revision, or uni- } \\
\text { compartmental TKA. }\end{array}$ & $\begin{array}{l}\text { Age } \\
\text { ASA } \\
\text { BMI }\end{array}$ & 383 & $\begin{array}{l}64( \pm \\
10)\end{array}$ & $214(56)$ & $\begin{array}{l}\text { Univariate } \\
\text { and } \\
\text { Multivariable } \\
\text { regression }\end{array}$ \\
\hline $\begin{array}{l}\text { D'Apuzzo } \\
\text { et al., } 2015 . \\
\text { USA }\end{array}$ & $\begin{array}{l}\text { The John Insall Award: Morbid } \\
\text { Obesity Independently Impacts } \\
\text { Complications, Mortality, and } \\
\text { Resource Use After TKA. }\end{array}$ & $\begin{array}{l}\text { Retrospective matched cohort; } \\
\text { Obesity, due to the nature of the } \\
\text { study, was excluded from the } \\
\text { matching criteria. Morbidly obese } \\
\text { patients who could not be } \\
\text { matched were excluded. }\end{array}$ & BMI & 180,585 & $\begin{array}{l}61 \\
(22- \\
90)\end{array}$ & $\begin{array}{l}135,541 \\
(75)\end{array}$ & Univariate \\
\hline $\begin{array}{l}\text { Murphy et al., } \\
\text { 2018. Australia }\end{array}$ & $\begin{array}{l}\text { The Impact of Older Age on Patient } \\
\text { Outcomes Following Primary Total } \\
\text { Knee Arthroplasty. }\end{array}$ & Retrospective cohort & $\begin{array}{l}\text { Age } \\
\text { ASA } \\
\text { BMI } \\
\text { CCl } \\
\text { Gender } \\
\text { SF-12 PROM } \\
\text { SES } \\
\text { Smoking }\end{array}$ & 2838 & $\begin{array}{l}70( \pm \\
9)\end{array}$ & $\begin{array}{l}1882 \\
(66)\end{array}$ & $\begin{array}{l}\text { Univariate } \\
\text { and } \\
\text { Multivariable } \\
\text { regression }\end{array}$ \\
\hline $\begin{array}{l}\text { Prohaska et al., } \\
\text { 2017. USA }\end{array}$ & $\begin{array}{l}\text { Preoperative Body Mass Index and } \\
\text { Physical Function are Associated } \\
\text { with Length of Stay and Facility } \\
\text { Discharge after Total Knee } \\
\text { Arthroplasty }\end{array}$ & $\begin{array}{l}\text { Prospective cohort; } \\
\text { Bilateral procedures, simultaneous } \\
\text { and staged within one year, and } \\
\text { those with concomitant joint } \\
\text { arthroplasty or ligament repair on } \\
\text { the ipsilateral extremity were } \\
\text { excluded. }\end{array}$ & $\begin{array}{l}\text { Age } \\
\text { BMl } \\
\text { CCl } \\
\text { Gender } \\
\text { Hemoglobin } \\
\text { Smoking } \\
\text { VR-12 PROM }\end{array}$ & 716 & $\begin{array}{l}63( \pm \\
11)\end{array}$ & $425(59)$ & $\begin{array}{l}\text { Univariate } \\
\text { and } \\
\text { Multivariable } \\
\text { regression }\end{array}$ \\
\hline $\begin{array}{l}\text { Rissman et al., } \\
\text { 2016. USA }\end{array}$ & $\begin{array}{l}\text { Predictors of Facility Discharge, } \\
\text { Range of Motion, and Patient- } \\
\text { Reported Physical Function Improve- } \\
\text { ment After Primary Total Knee } \\
\text { Arthroplasty: A Prospective Cohort } \\
\text { Analysis }\end{array}$ & $\begin{array}{l}\text { Prospective cohort; } \\
\text { Simultaneous bilateral TKAs were } \\
\text { excluded. }\end{array}$ & $\begin{array}{l}\text { Age } \\
\text { BMI } \\
\text { CCl } \\
\text { Gender } \\
\text { ROM } \\
\text { VR-12 PROM }\end{array}$ & 738 & $\begin{array}{l}64( \pm \\
10)\end{array}$ & $422(57)$ & $\begin{array}{l}\text { Univariate } \\
\text { and } \\
\text { Multivariable } \\
\text { regression }\end{array}$ \\
\hline $\begin{array}{l}\text { Sayeed et al. } \\
\text { 2016. USA }\end{array}$ & $\begin{array}{l}\text { Comparing In-Hospital Total Joint } \\
\text { Arthroplasty Outcomes and Re- } \\
\text { source Consumption Among Under- } \\
\text { weight and Morbidly Obese Patients }\end{array}$ & $\begin{array}{l}\text { Retrospective matched cohort; } \\
\text { Weight loss and obesity, due to the } \\
\text { nature of the study, were excluded } \\
\text { from the matching criteria. }\end{array}$ & BMI & 956 & $\begin{array}{l}67 \\
(15- \\
91)\end{array}$ & 791 (83) & Univariate \\
\hline $\begin{array}{l}\text { Schwarzkopf } \\
\text { et al., } 2016 . \\
\text { USA }\end{array}$ & $\begin{array}{l}\text { Factors Influencing Discharge } \\
\text { Destination } \\
\text { After Total Knee Arthroplasty: } \\
\text { A Database Analysis }\end{array}$ & Retrospective cohort & $\begin{array}{l}\text { Age } \\
\text { CCl } \\
\text { Gender } \\
\text { Ethnicity }\end{array}$ & 28,611 & 68 & $\begin{array}{l}17,930 \\
(63)\end{array}$ & $\begin{array}{l}\text { Multinomial } \\
\text { regression }\end{array}$ \\
\hline $\begin{array}{l}\text { Sikora-Klak } \\
\text { et al., } 2016 . \\
\text { USA }\end{array}$ & $\begin{array}{l}\text { The Effect of Comorbidities on } \\
\text { Discharge Disposition and } \\
\text { Readmission for Total Joint } \\
\text { Arthroplasty Patients }\end{array}$ & $\begin{array}{l}\text { Retrospective cohort } \\
\text { Bilateral procedures were excluded } \\
\text { as were patients undergoing joint } \\
\text { arthroplasty for fracture. }\end{array}$ & $\begin{array}{l}\text { Age } \\
\text { BMl } \\
\text { Diabetes } \\
\text { Gender } \\
\text { Smoking } \\
\text { VTE history }\end{array}$ & 2009 & $\begin{array}{l}65( \pm \\
11)\end{array}$ & $\begin{array}{l}1347 \\
(67)\end{array}$ & $\begin{array}{l}\text { Univariate } \\
\text { and } \\
\text { Multivariable } \\
\text { regression }\end{array}$ \\
\hline
\end{tabular}

Abbreviations: ASA American society of anesthesiologists, BMI body mass index $(\mathrm{kg} / \mathrm{m} 2), C C l$ Charlson comorbidity index, $H b$ Hemoglobin, $R O M$ range of motion, SES socioeconomic status, SF-12 12 item Short Form Health Survey (physical component score), VR-12 Veterans RAND 12 Item Health Survey, VTE Venous thromboembolism

${ }^{\text {a }}$ Predictors and Statistical Analysis are in reference to the outcome of interest, Discharge Destination

destination. Being of female gender increased the likelihood of IRF discharge by $78 \%$ when compared to male gender $(\mathrm{OR}=1.78 ; 95 \% \mathrm{CI}=1.43-2.20)$ (Fig. 2). The association between age and discharge destination was reported in 6 studies [20, 22-24, 26, 27]. Older age was predictive of IRF discharge in all included studies, with 
Table 3 Results of risk of bias assessment using the Quality in Prognosis Studies (QUIPS) tool for included studies

\begin{tabular}{lllllll}
\hline Study & $\begin{array}{l}\text { Study } \\
\text { participation }\end{array}$ & $\begin{array}{l}\text { Study } \\
\text { attrition }\end{array}$ & $\begin{array}{l}\text { Prognostic factor } \\
\text { measurement }\end{array}$ & $\begin{array}{l}\text { Outcome } \\
\text { measurement }\end{array}$ & $\begin{array}{l}\text { Study } \\
\text { confounding }\end{array}$ & $\begin{array}{l}\text { Statistical analysis and } \\
\text { reporting }\end{array}$ \\
\hline Anoushiravani & Low & Low & Low & Low & Moderate & Low \\
Crawford & Low & Low & Low & Low & Moderate & Moderate \\
D'Apuzzo & Low & Low & Low & Low & Low & Low \\
Murphy & Low & Low & Low & Low & Low & Low \\
Prohaska & Low & Low & Low & Low & Low & Low \\
Rissman & Low & Low & Low & Low & Moderate & Moderate \\
Sayeed & Low & Low & Low & Low & High & Low
\end{tabular}

Study participation = the representativeness of the study sample; Study attrition = whether participants with follow-up data represent persons enrolled in the study; Prognostic factor measurement = adequacy of prognostic factor measurement; Outcome measurement = adequacy of outcome measurement; Study confounding = potential confounding factors; Statistical analysis and reporting $=$ the appropriateness of the statistical analysis and completeness of reporting

the greatest effect for those aged 75 years and older (Fig. 3). Increased BMI was also able to be included for review in 3 studies [22-24], with those in the severely obese $\left(\geq 40 \mathrm{~kg} / \mathrm{m}^{2}\right)$ category having the highest likelihood of IRF discharge (Fig. 4).

\section{Clinical factors}

Studies varied in their reporting of patient comorbidities. CCI was reported in 3 studies but due to methodological heterogenicity could not be meta-analysed [22-24]. The CCI quantifies an individual's burden of disease and corresponding 1-year mortality risk, with a lower score equalling a lower risk [28]. Figure 5 shows a trend was towards a higher CCI being more predictive of IRF discharge.

\section{Behavioural factors}

Smoking status (non-smoker or currently smoking) was reported on in 3 studies and was included in metaanalysis [22, 23, 27]. Smoking showed an overall decreased likelihood of IRF discharge $(\mathrm{OR}=0.80 ; 95 \% \mathrm{CI}$

Table 4 Intrinsic Patient Factors Predictive of Inpatient Rehabilitation Discharge

\begin{tabular}{|c|c|c|c|c|c|c|c|c|c|c|}
\hline & Anoushiravani & Crawford & D’Apuzzo & Murphy & Prohaska & Rissman & Sayeed & Schwarzkopf & Sikora-Klak & Total \\
\hline Age (older) & - & $\checkmark \checkmark$ & - & $\checkmark \checkmark$ & $\checkmark \checkmark$ & $\checkmark \checkmark$ & - & $\checkmark^{b}$ & $\checkmark \checkmark$ & $6 / 6$ \\
\hline ASA (higher) & - & $\checkmark \checkmark$ & - & $\checkmark$ & - & - & - & - & - & $2 / 2$ \\
\hline BMI (higher) & $\boldsymbol{\checkmark}^{\mathrm{a}, \mathrm{b}}$ & $x^{b}$ & $\checkmark^{b}$ & $\checkmark \checkmark$ & $\checkmark \checkmark$ & $\checkmark \checkmark$ & $x^{b}$ & - & - & $5 / 7$ \\
\hline CCI (higher) & - & - & - & $\checkmark \checkmark$ & $\checkmark \checkmark$ & $\checkmark \checkmark$ & - & $\checkmark \checkmark^{\mathrm{b}}$ & & $4 / 4$ \\
\hline Diabetes (yes) & - & - & - & - & - & - & - & - & $\checkmark \checkmark$ & $1 / 1$ \\
\hline Gender (Female) & - & - & - & $\checkmark \checkmark$ & $\checkmark \checkmark$ & $\checkmark \checkmark$ & - & $\checkmark^{b}$ & $\checkmark \checkmark$ & $5 / 5$ \\
\hline Ethnicity (non-caucasian) & - & - & - & - & - & - & - & $\checkmark \checkmark$ & - & $1 / 1$ \\
\hline Hb (lower) & - & - & - & - & $\checkmark \checkmark$ & - & - & - & - & $1 / 1$ \\
\hline Knee ROM (lower) & - & - & - & - & - & $x$ & - & - & - & $0 / 1$ \\
\hline SES (lower) & - & - & - & $\checkmark \checkmark$ & - & - & - & - & - & $1 / 1$ \\
\hline SF-12/VR-12 (lower) & - & - & - & $\checkmark \checkmark$ & $\checkmark \checkmark$ & $\checkmark \checkmark$ & - & - & - & $3 / 3$ \\
\hline Smoking (yes) & - & - & - & $\checkmark \checkmark$ & $x$ & - & - & - & $\checkmark$ & $2 / 3$ \\
\hline VTE History (yes) & - & - & - & - & - & - & - & - & $\checkmark \checkmark$ & $1 / 1$ \\
\hline
\end{tabular}

Abbreviations: ASA American society of anesthesiologists, $B M I$ body mass index $\left(\mathrm{kg} / \mathrm{m}^{2}\right), C C l$ Charlson comorbidity index, $\mathrm{Hb}$ Hemoglobin, $R O M$ range of motion, SES socioeconomic status, SF-12 12 item Short Form Health Survey (physical component score), VR-12 Veterans RAND 12 Item Health Survey, VTE

Venous thromboembolism

${ }^{\mathrm{a}} \mathrm{BMI}<19 \mathrm{~kg} / \mathrm{m}^{2}$ (Underweight patients)

${ }^{\mathrm{b}}$ Factor not able to undergo pooled analysis due to statistical reporting heterogeneity

$\checkmark \checkmark=$ Factor significant in multivariable analysis $\checkmark=$ Factor only significant in univariate analysis $x=$ Factor not significant in univariate analysis - indicates that a factor was not assessed 


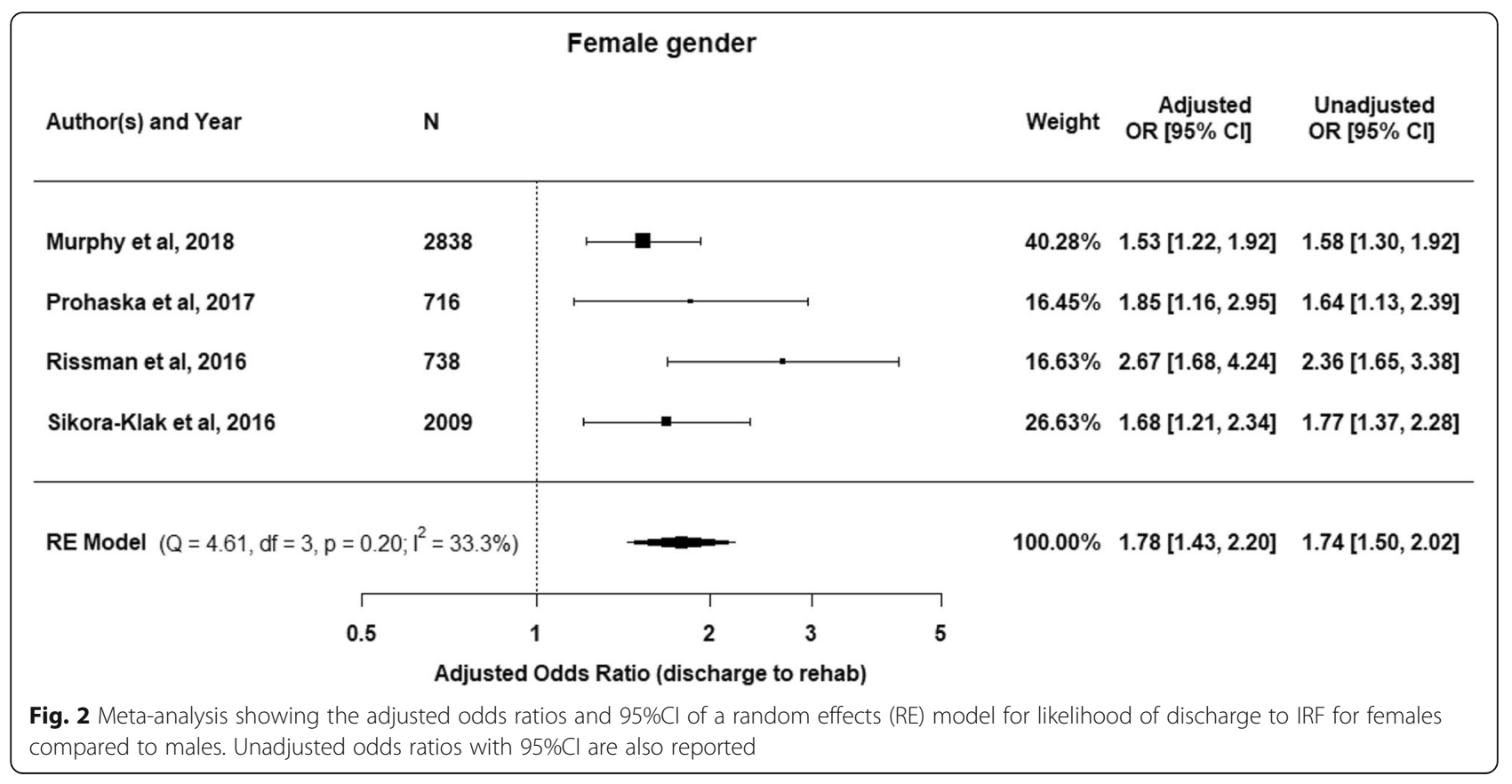

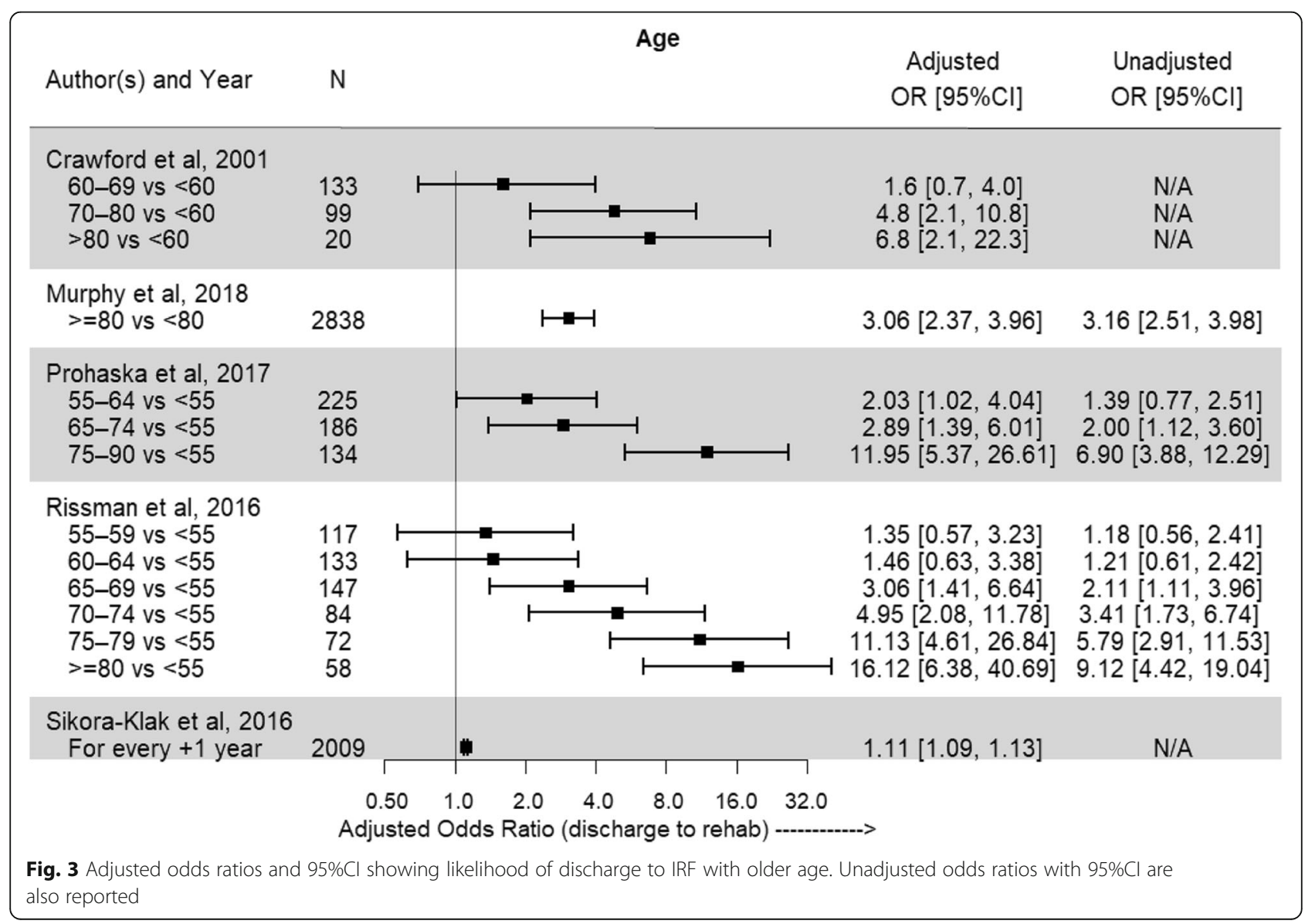




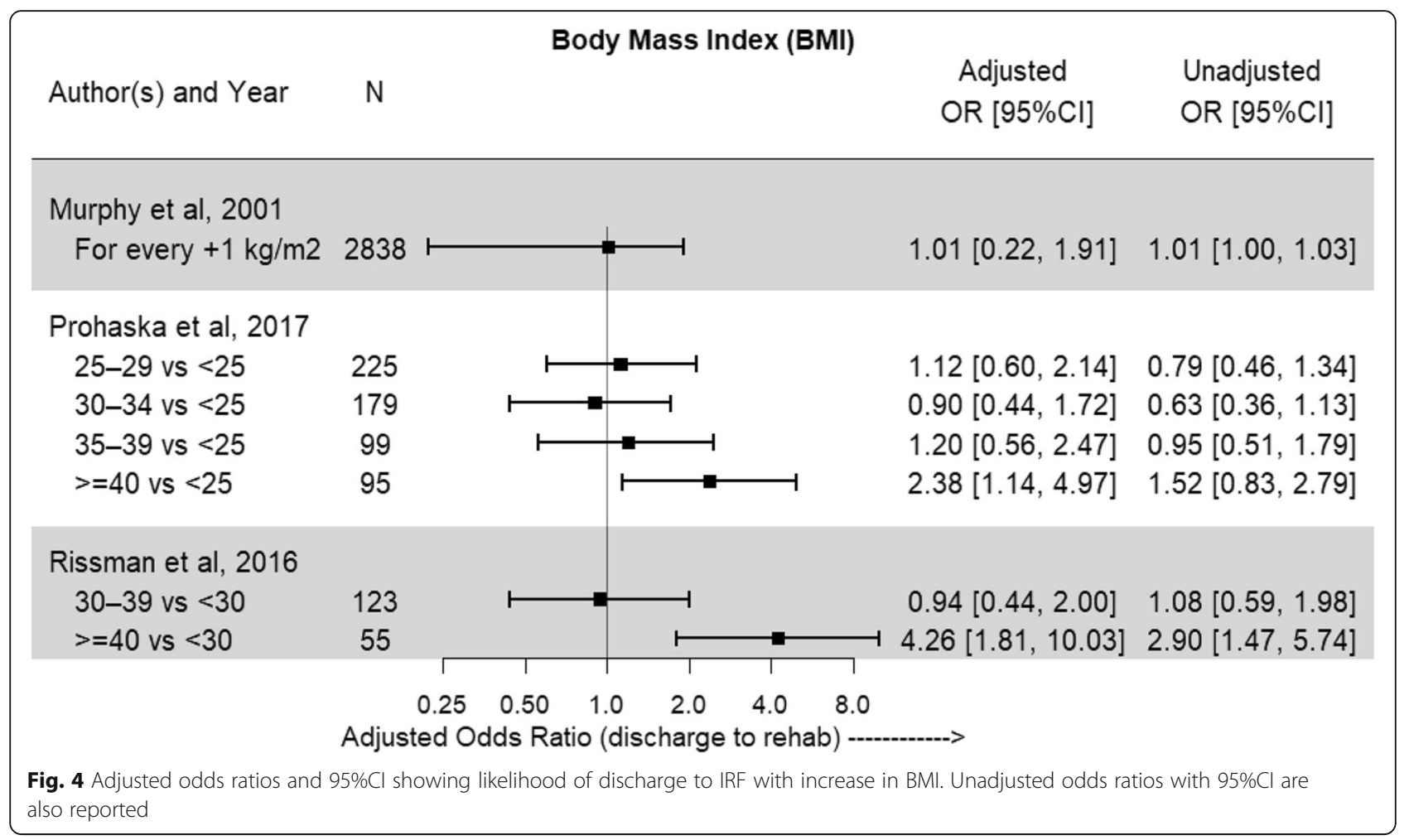

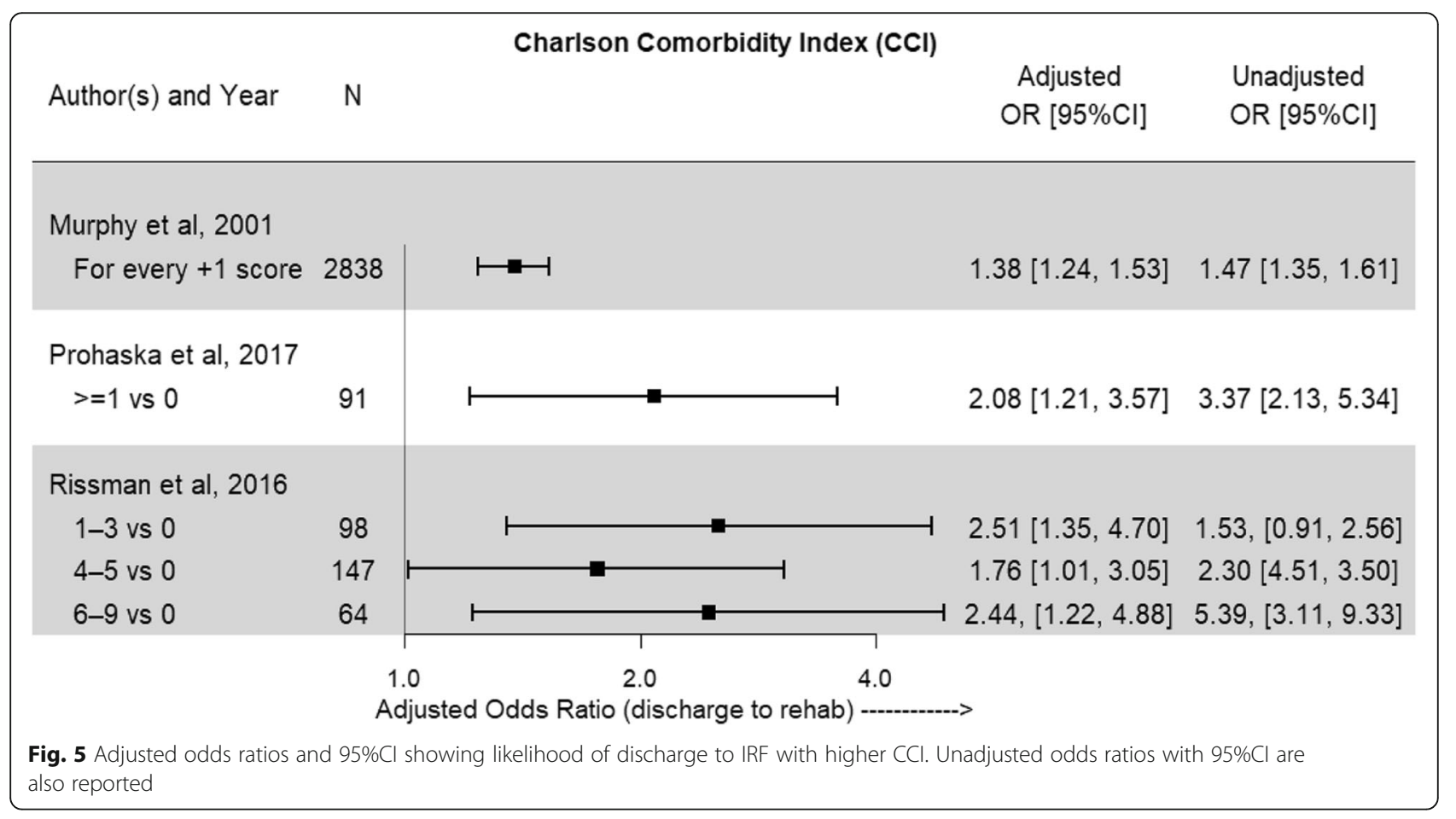




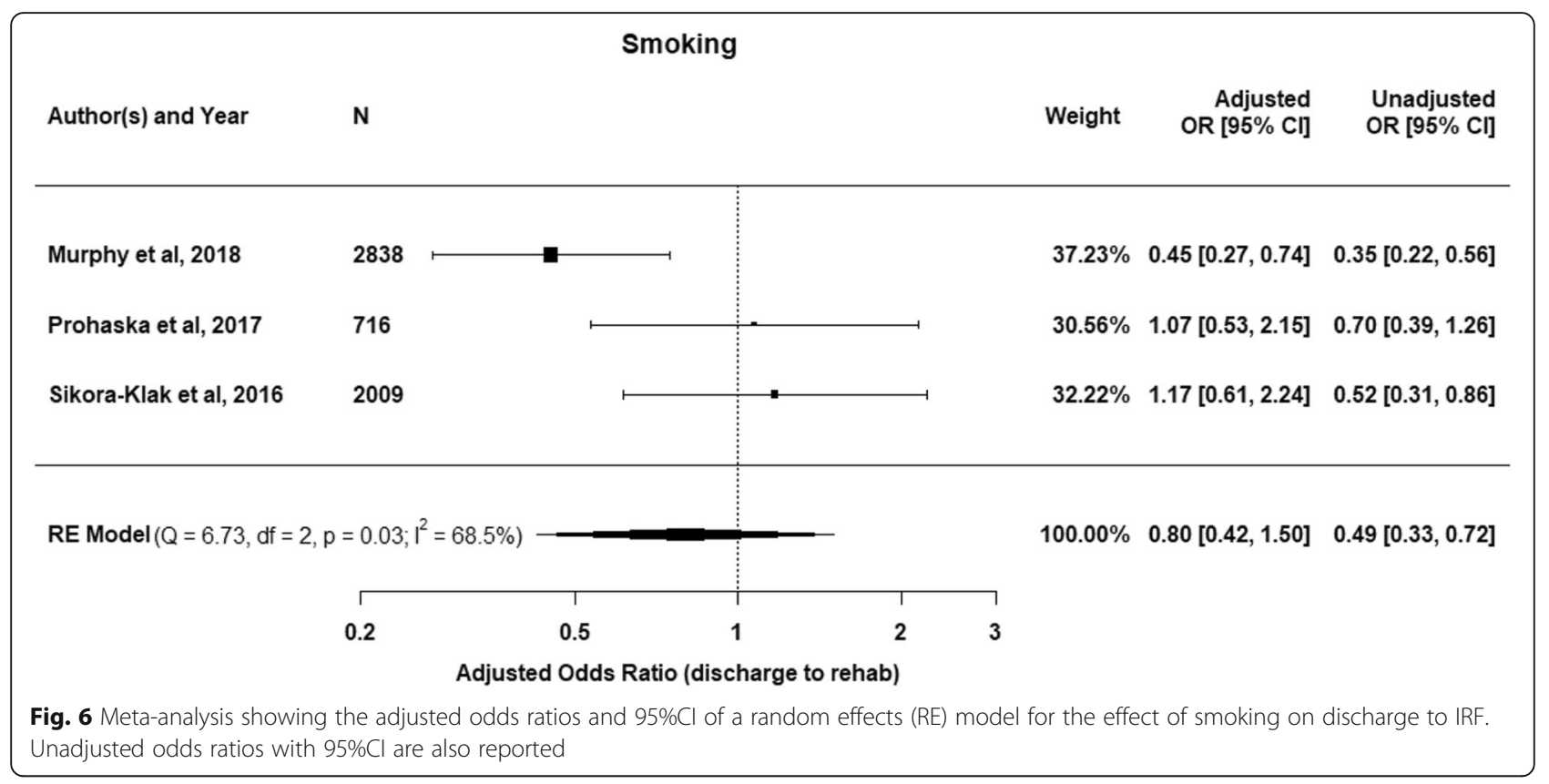

0.42-1.50), however, heterogeneity of the studies was moderate $\left(I^{2}=68.5 \%\right)$ (Fig. 6).

\section{Patient reported outcome measures}

A self-reported measure of physical function was assessed in 3 [22-24] of the 9 included studies, and due to the similarity of the design and scoring systems of the
SF-12 and VR-12 it was decided to combine the results of these tools (Fig. 7) [29, 30]. Only 1 study, Prohaska et al., demonstrated a consistent association with IRF discharge related to lower self-reported physical function, with the other included studies showing the relationship to be more unclear.

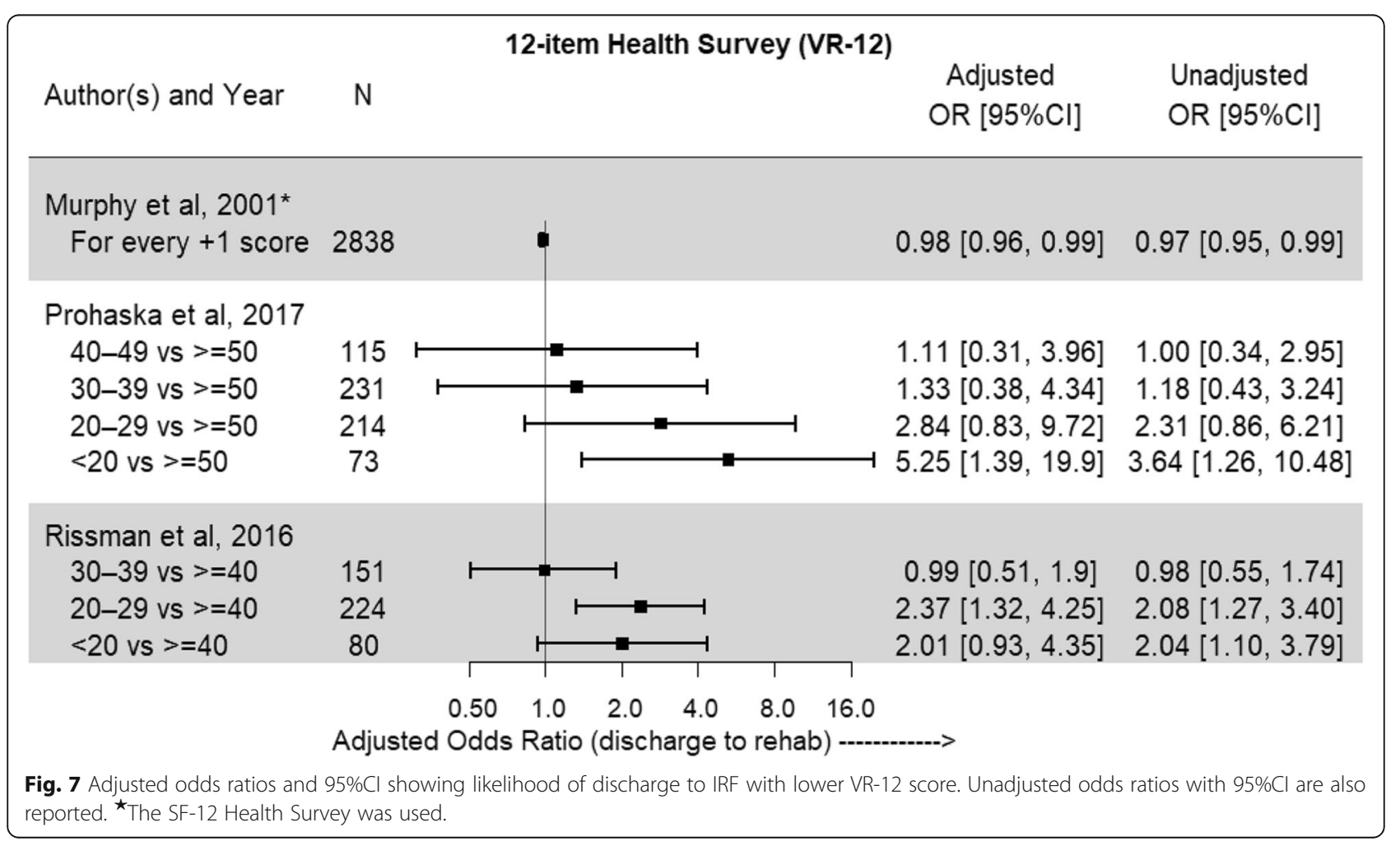




\section{Discussion}

This systematic review and meta-analysis demonstrates that it is difficult to develop predictive models for intrinsic patient factors associated with IRF discharge based on the current existing literature. The large degree of heterogeneity and wide variation of statistical analysis and reporting across the included studies precluded meta-analysis for all but 2 variables. Two included factors underwent meta-analysis, gender and smoking (Figs. 2 and 6). There was a clear association between female gender and likelihood of IRF discharge, however, the relationship between smoking status and IRF discharge was less certain due to the heterogeneity of the studies included in the smoking meta-analysis $\left(I^{2}=68.5 \%\right)$. For the other intrinsic patient factors included in this review, the strongest trends for discharge to IRF were older age, greater comorbidity or the severely obese. A worse self-reported physical function was not consistently associated with an increased risk for IRF discharge.

Although to our knowledge this is the first systematic literature review and meta-analysis where the primary outcome of interest is discharge destination, systematic reviews on patient factors predictive of increased length of hospital stay following TJA have been published [31, 32]. The patient risk factors found in this review that trended towards an increased likelihood of discharge to IRF, are similar to those reported for increased length of stay, including female gender, older age, increased comorbidities and higher BMI [31, 32].

A limitation of this review is that the studies included were mostly of retrospective design and all utilised large medical databases as the source of patient predictors. The use of large databases for analysis has been reported as having limitations such as coding bias [33]. Additionally, using a retrospective cohort design limits the investigation to only variables recorded at that time. It is likely that other surgical, psychological and sociological variables could be predictive of discharge destination, however, if this information is not available at the time of retrospective data collection then it will not be included in analysis. In terms of sociological factors, insurance status has been shown to be predictive of IRF discharge [34], however, due to the international variability of insurance models this was excluded from analysis.

One psychological variable that has been shown to be predictive of discharge destination following TJA is patient expectation [35]. Halawi et al. found that a patient's preoperative expectation of their discharge destination was the strongest predictor of actual discharge destination even when adjusted for other variables such as age and caregiver assistance. As this study did not separate TKA from total hip arthroplasty it was not eligible for inclusion in this review, but it does highlight the need for more studies incorporating patient belief systems into predictive modelling for IRF discharge.

With a growing body of evidence suggesting that IRF discharge following routine primary TKA is not superior to home discharge, further prospective high-quality studies investigating the patient factors that are predictive of discharge destination are needed. Previous studies have assessed patient factors by retrospectively accessing medical records, however, many of these are nonmodifiable such as age and gender. With significantly increased costs associated with IRF when compared with home discharge after TKA, modifiable patient factors such as BMI and patient expectation should be given priority in future investigations.

\section{Conclusion}

This systematic review and meta-analysis illustrates that although literature exists on investigating which intrinsic patient factors are predictive of IRF discharge, there is large variation in statistical methods and reporting. Female gender and smoking were two patient factors able to be included in this meta-analysis, with female gender shown to be predictive of IRF discharge, however, the relationship between smoking and discharge destination was less certain. There was also a trend for those of older age, increased comorbidity or in a severely obese category to have an increased likelihood of IRF discharge.

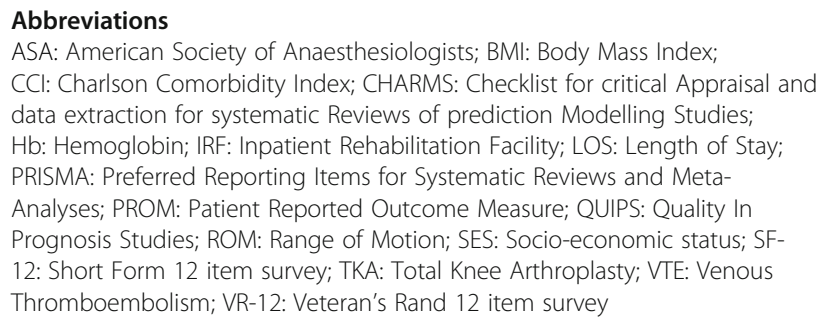

\section{Acknowledgements}

Not applicable.

\section{Authors' contributions}

LS carried out the search and screening process, and LS \& WH assessment of study quality. LS and WH drafted the manuscript. LS, WH and CV edited the manuscript. LS and CV conceived the study, and CV provided key expert input and editing throughout the process. ER provided input on methodology and statistical analysis and LS assisted with statistical analysis. WH provided feedback on methodological and statistical aspects. All authors read and approved the final manuscript.

\section{Authors' information}

Not applicable.

\section{Funding}

This was an unfunded study. The authors certify that they have no affiliations with or financial involvement in any organization or entity with a direct financial interest in the subject matter or materials discussed in the article.

Availability of data and materials

All data generated or analysed during this study are included in this published article. 


\section{Ethics approval and consent to participate}

Not applicable.

\section{Consent for publication}

Not applicable.

\section{Competing interests}

The authors declare that they have no competing interests.

\section{Author details}

${ }^{1}$ Bond University, Bond Institute of Health and Sport, Promethean Way, Robina, QLD 4226, Australia. ${ }^{2}$ Knee Research Australia, 8-10 Carrara Street, Benowa, QLD 4217, Australia.

Received: 24 January 2020 Accepted: 13 July 2020

Published online: 22 July 2020

\section{References}

1. Sloan M, Premkumar A, Sheth NP. Projected volume of primary Total joint Arthroplasty in the U.S., 2014 to 2030. JBJS. 2018;100(17):1455-60. https:// doi.org/10.2106/jbjs.17.01617

2. Ho DM, Huo MH. Are critical pathways and implant standardization programs effective in reducing costs in total knee replacement operations? J Am Coll Surg. 2007;205(1):97-100. https://doi.org/10.1016/j.jamcollsurg.2007.03.009.

3. Kurtz SM, Ong KL, Lau E, Bozic KJ. Impact of the economic downturn on total joint replacement demand in the United States: updated projections to 2021. J Bone Joint Surg. 2014;96(8):624. https://doi.org/10.2106/JBJS.M. 00285 American volume.

4. Healy WL, Rana AJ, lorio R. Hospital economics of primary Total knee Arthroplasty at a teaching hospital. Clin Orthop Relat Res. 2011;469(1):87-94. https://doi.org/10.1007/s11999-010-1486-2.

5. DeJong G, Horn SD, Smout RJ, Tian W, Putman K, Gassaway J. Joint replacement rehabilitation outcomes on discharge from skilled nursing facilities and inpatient rehabilitation facilities. Arch Phys Med Rehabil. 2009; 90(8):1284-96. https://doi.org/10.1016/j.apmr.2009.02.009.

6. Mayer MA, Pirruccio K, Sloan M, Sheth NP. Discharge home is associated with decreased early complications following primary Total joint Arthroplasty. J Arthroplast. 2019;34(11):2586-93. https://doi.org/10.1016/j.arth.2019.06.049.

7. Ramos NL, Wang EL, Karia RJ, Hutzler LH, Lajam CM, Bosco JA. Correlation between physician specific discharge costs, LOS, and 30-day readmission rates: an analysis of 1,831 cases. J Arthroplast. 2014;29(9):1717-22. https:// doi.org/10.1016/j.arth.2014.04.005.

8. Buhagiar MA, Naylor JM, Harris IA, Xuan W, Kohler F, Wright R, Fortunato R. Effect of inpatient rehabilitation vs a monitored home-based program on mobility in patients with Total knee Arthroplasty: The HIHO randomized clinical trial. Jama. 2017;317(10):1037-46. https://doi.org/10.1001/jama.2017.1224.

9. Li D, Yang Z, Kang P, Xie X. Home-based compared with hospital-based rehabilitation program for patients undergoing Total knee Arthroplasty for osteoarthritis: a systematic review and meta-analysis of randomized controlled trials. Am J Phys Med Rehabil. 2017;96(6):440-7. https://doi.org/ 10.1097/phm.0000000000000621.

10. Keswani A, Tasi MC, Fields A, Lovy AJ, Moucha CS, Bozic KJ. Discharge destination after Total joint Arthroplasty: an analysis of Postdischarge outcomes, placement risk factors, and recent trends. J Arthroplast. 2016; 31(6):1155-62. https://doi.org/10.1016/j.arth.2015.11.044.

11. Ramos NL, Karia RJ, Hutzler LH, Brandt AM, Slover JD, Bosco JA. The effect of discharge disposition on 30-day readmission rates after Total joint Arthroplasty. J Arthroplast. 2014;29(4):674-7. https://doi.org/10.1016/j.arth.2013.09.010.

12. Sharareh B, Le NB, Hoang MT, Schwarzkopf R. Factors determining discharge destination for patients undergoing Total joint Arthroplasty. J Arthroplast. 2014; 29(7):1355-1358.e1351. https:/doi.org/10.1016/j.arth.2014.02.001.

13. Moher D, Liberati A, Tetzlaff J, Altman DG, The PG. Preferred reporting items for systematic reviews and meta-analyses: The PRISMA statement. PLoS Med. 2009;6(7):e1000097. https://doi.org/10.1371/journal.pmed.1000097.

14. Moons KGM, de Groot JAH, Bouwmeester W, Vergouwe Y, Mallett S, Altman $D G$, et al. Critical appraisal and data extraction for systematic reviews of prediction Modelling studies: The CHARMS checklist. PLoS Med. 2014;11(10): e1001744. https://doi.org/10.1371/journal.pmed.1001744.

15. Hayden $J A$, Cote $P$, Bombardier C. Evaluation of the quality of prognosis studies in systematic reviews. Ann Intern Med. 2006;144(6):427-37. https:// doi.org/10.7326/0003-4819-144-6-200603210-00010.
16. Hayden JA, van der Windt DA, Cartwright JL, Cote P, Bombardier C. Assessing bias in studies of prognostic factors. Ann Intern Med. 2013;158(4): 280-6. https://doi.org/10.7326/0003-4819-158-4-201302190-00009.

17. R Core Team. R: A language and environment for statistical computing. Vienna: R Foundation for Statistical Computing; 2013. URL http://www.Rproject.org/.

18. Higgins JP, Thompson SG, Deeks JJ, Altman DG. Measuring inconsistency in meta-analyses. BMJ. 2003;327(7414):557-60. https://doi.org/10.1136/bmj.327. 7414.557.

19. Anoushiravani AA, Sayeed Z, Chambers MC, Gilbert TJ, Scaife SL, El-Othmani MM, Saleh KJ. Assessing in-hospital outcomes and resource utilization after primary Total joint Arthroplasty among underweight patients. J Arthroplast. 2016;31(7):1407-12. https://doi.org/10.1016/j.arth.2015.12.053.

20. Crawford DA, Scully W, McFadden L, Manoso M. Preoperative predictors of length of hospital stay and discharge disposition following primary total knee arthroplasty at a military medical center. Mil Med. 2011;176(3):304-7. https://doi.org/10.7205/milmed-d-10-00042.

21. D'Apuzzo MR, Novicoff WM, Browne JA. The John Insall award: morbid obesity independently impacts complications, mortality, and resource use after TKA. Clin Orthop Relat Res. 2015;473(1):57-63. https://doi.org/10.1007/ s11999-014-3668-.

22. Murphy BPD, Dowsey MM, Spelman T, Choong PFM. The impact of older age on patient outcomes following primary total knee arthroplasty. Bone Joint J. 2018;100-b(11):1463-70. https://doi.org/10.1302/0301-620x.100b11. Bjj-2017-0753.R6.

23. Prohaska MG, Keeney BJ, Beg HA, Swarup I, Moschetti WE, Kantor SR, Tomek IM. Preoperative body mass index and physical function are associated with length of stay and facility discharge after total knee arthroplasty. Knee. 2017 24(3):634-40. https://doi.org/10.1016/j.knee.2017.02.005.

24. Rissman CM, Keeney BJ, Ercolano EM, Koenig KM. Predictors of facility discharge, range of motion, and patient-reported physical function improvement after primary Total knee Arthroplasty: a prospective cohort analysis. J Arthroplast. 2016;31(1):36-41. https://doi.org/10.1016/j.arth.2015. 09.002 .

25. Sayeed Z, Anoushiravani AA, Chambers MC, Gilbert TJ, Scaife SL, El-Othmani MM, Saleh KJ. Comparing in-hospital Total joint Arthroplasty outcomes and resource consumption among underweight and morbidly obese patients. J Arthroplast. 2016;31(10):2085-90. https://doi.org/10.1016/j.arth.2016.03.

26. Schwarzkopf R, Ho J, Quinn JR, Snir N, Mukamel D. Factors influencing discharge destination after Total knee Arthroplasty: a database analysis. Geriatr Orthop Surg Rehabil. 2016;7(2):95-9. https://doi.org/10.1177/ 2151458516645635.

27. Sikora-Klak J, Zarling B, Bergum C, Flynn JC, Markel DC. The effect of comorbidities on discharge disposition and readmission for Total joint Arthroplasty patients. J Arthroplast. 2017;32(5):1414-7. https://doi.org/10. 1016/j.arth.2016.11.035.

28. Charlson ME, Pompei P, Ales KL, Mackenzie CR. A new method of classifying prognostic comorbidity in longitudinal studies: development and validation. J Chronic Dis. 1987;40(5):373-83. https://doi.org/10.1016/00219681(87)90171-8.

29. Ware JE, Kosinski M, Keller S. SF-36 physical and mental health summary scales. In: A user's manual, 1994; 2001.

30. Lee A, Browne MO, Villanueva E. Consequences of using SF-12 and RAND12 when examining levels of well-being and psychological distress. Aust N Z J Psychiatry. 2008;42(4):315-23. https://doi.org/10.1080/ 00048670701881579

31. Elings J, Hoogeboom TJ, van der Sluis G, van Meeteren NLU. What preoperative patient-related factors predict inpatient recovery of physical functioning and length of stay after total hip arthroplasty? A systematic review. Clin Rehabil. 2014;29(5):477-92. https://doi.org/10.1177/ 0269215514545

32. Shah A, Memon M, Kay J, Wood TJ, Tushinski DM, Khanna V. Preoperative patient factors affecting length of stay following Total knee Arthroplasty: a systematic review and meta-analysis. J Arthroplast. 2019;34(9):2124-2165. e2121. https://doi.org/10.1016/j.arth.2019.04.048.

33. Yoshihara H, Yoneoka D. Understanding the statistics and limitations of large database analyses. Spine (Phila Pa 1976). 2014;39(16):1311-2. https:// doi.org/10.1097/brs.0000000000000352.

34. Naylor JM, Hart A, Harris IA, Lewin AM. Variation in rehabilitation setting after uncomplicated total knee or hip arthroplasty: a call for evidence-based 
guidelines. BMC Musculoskelet Disord. 2019;20(1):214. https://doi.org/10. 1186/s12891-019-2570-8.

35. Halawi MJ, Vovos TJ, Green CL, Wellman SS, Attarian DE, Bolognesi MP.

Patient expectation is the Most important predictor of discharge destination

after primary Total joint Arthroplasty. J Arthroplast. 2015;30(4):539-42. https://doi.org/10.1016/j.arth.2014.10.031.

\section{Publisher's Note}

Springer Nature remains neutral with regard to jurisdictional claims in published maps and institutional affiliations.

Ready to submit your research? Choose BMC and benefit from:

- fast, convenient online submission

- thorough peer review by experienced researchers in your field

- rapid publication on acceptance

- support for research data, including large and complex data types

- gold Open Access which fosters wider collaboration and increased citations

- maximum visibility for your research: over $100 \mathrm{M}$ website views per year

At $\mathrm{BMC}$, research is always in progress.

Learn more biomedcentral.com/submissions 